\title{
Tıbbi Amaçlı Kullanılan Terminalia chebula ve Terminalia citrina Bitkilerinin Kurutulmuş Meyvelerinde Antiradikal, Antibakteriyel ve Mutajenik Aktivite Analizleri
}

\author{
Zehra Tuğba MURATHAN*1(D), Nurcan ERBiL ${ }^{2}$ (D), Mehmet ARSLAN ${ }^{3}$ \\ ${ }^{1}$ Malatya Turgut Özal Üniversitesi, Battalgazi Meslek Yüksekokulu, Park ve Bahçe Bitkileri Bölümü, \\ Battalgazi/Malatya \\ ${ }^{2}$ Ardahan Üniversitesi, Sağlık Bilimleri Fakültesi, Hemşirelik Bölümü, Ardahan \\ ${ }^{3}$ Ardahan Üniversitesi, Sağlık Bilimleri Fakültesi, Sağlık Yönetimi Bölümü, Ardahan
}

Öz: Terminalia cinsi üyeleri Combretaceae familyasındandırlar. Cinse ait yaklaşık 250 tür bulunmaktadır. Bu türler içerisinde özellikle Terminalia chebula ve Terminalia citrina bazı hastalıkların önlenmesinde geleneksel olarak halk tıbbında kullanılmaktadır. Türkiye'de bu bitkilerin kurutulmuş meyveleri sırasıyla kara ve sarı halile olarak adlandırımaktadır. Bu çalışmada, aktarlarda yoğun olarak satılan ve halk tarafından çeşitli amaçlarla kullanılan $T$. chebula ve $T$. citrina bitkilerine ait kurutulmuş meyvelerde bazı biyoaktif bileşen içerikleri, antioksidan kapasite, antibakteriyel ve mutajenik aktiviteler analiz edilmiştir. Toplam fenolik madde içerikleri $T$. citrina'da 108.3, $T$. chebula'da $226.3 \mathrm{mg}$ GAE/g değerlerinde, toplam flavanoid madde içerikleri ise $T$. chebula'da 40.7, T. citrina'da $55.9 \mathrm{mg}$ QE/g değerlerinde tespit edilmiştir. Antioksidan aktivite analizleri üç farklı metoda göre (ABTS (2,2'-azino-bis(3-ethylbenzothiazoline-6-sulfonic acid), DPPH (1,1-diphenyl-2picrylhydrazyl) ve FRAP (Demir iyonu indirgeyici antioksidan güç)) yapılmıştır. Her üç metoda göre de $T$. chebula örneklerinin $T$. citrina örneklerine göre daha yüksek antioksidan aktiviteye sahip olduğu belirlenmiştir. $T$. citrina ve $T$. chebula'nın metanol ekstraklarının test bakterilerine karşı oldukça iyi seviyede antibakteriyel etki gösterdiği, her iki ekstrakta karşı ise en duyarlı bakterinin Bacillus subtilis subsp. spizizenii ATCC 6633 olduğu tespit edilmiştir. Kuru meyve ekstraktlarının farklı dört dozu (12.5, 25, 50 ve $100 \mu \mathrm{l} /$ plak) mutajenite deneylerinde kullanılmıştır. TA 98 ve TA 100 suşları üzerine her iki örnek ekstraktının en yüksek dozları ile TA 100 suşu üzerinde denenen $T$. citrina ekstraktının $50 \mu \mathrm{l} /$ plak dozları sitotoksik olarak tespit edilmiştir. T. chebula ve T. citrina ekstraktlarının Salmonella typhimurium TA 98 suşu üzerine etkisi her iki örneğin 50 $\mu \mathrm{l} /$ plak dozlarında çözücü kontrole göre istatistiksel olarak önemli bulunmuştur.

Anahtar Kelimeler: Fenolik, Flavanoid, Halile, Mutajenite, Terminalia

\begin{abstract}
Antiradical, Antibacterial and Mutagenic Activity Analysis of Dried Fruits of Terminalia Chebula and Terminalia Citrina Plants Used for Medical Purposes
\end{abstract}

Abstract: The members of the genus Terminalia belong to the Combretaceae family. There are about 250 species belonging to the genus. Among these species, Terminalia chebula and Terminalia citrina have traditionally been used in folk medicine to prevent certain diseases. Dried fruits of this plant is called Turkey black and yellow halile respectively. In this study, some bioactive components, antioxidant capacity, antibacterial and mutagenic activities were analyzed in dried fruits of $T$. chebula and $T$. citrina plants which are sold intensively in herbal and used for various purposes by the public. Total phenolic content was found to be $108.3 \mathrm{in} \mathrm{T.} \mathrm{citrina,} 226.3 \mathrm{mg}$ GAE / g in T. chebula, total flavanoid substance content was $40.7 \mathrm{in} \mathrm{T.} \mathrm{chebula} \mathrm{and} 55.9 \mathrm{mg} Q E / \mathrm{g}$ in T citrina. Antioxidant activity analysis according to three different methods (ABTS (2,2'-azino-bis (3-ethylbenzothiazoline-6-sulfonic acid)), DPPH (1,1-diphenyl-2-picrylhydrazyl) and FRAP (Ferric ion-reducing antioxidant power)). According to all three methods, T. chebula samples had higher antioxidant activity than T. citrina samples. T. citrina and $T$. chebula showed that the methanol extracts had a very good antibacterial effect against the test bacteria, while the most sensitive bacteria against both extracts were Bacillus subtilis subsp. spizizenii ATCC 6633. Four different doses of dried fruit extracts (12.5, 25, 50 and $100 \mathrm{\mu l} /$ plate) were used in mutagenicity experiments. The highest doses of both sample extracts on TA 98 and TA 100 strains and $50 \mu \mathrm{l} /$ plaque doses of T. citrina extract tested on TA 100 strains were found to be cytotoxic. The effect of T. chebula and T. citrina extracts on Salmonella typhimurium TA 98 strain was found to be statistically significant in $50 \mu l$ / plate doses of both samples compared to solvent control.

Keywords: Phenolic, Flavanoid, Halile, Mutagenity, Terminalia

\section{GíRiş}

İnsan vücudunda çevresel kirlilik, UV ışınları, toksik kimyasallar, sigara, alkol kullanımı gibi nedenlerle serbest radikaller üretilmektedir. Serbest radikallerin organizmada aşırı artışı oksidatif stres adı verilen durumu ortaya çıkarmaktadır. Bu radikaller hücrelerin membran lipidlerini, DNA'sını ve proteinlerini potansiyel hedef olarak görmekte ve bu moleküllere zarar vererek kanser, damar sertleşmesi, iltihabi hastalıklar, yaşlanma, kalp hastalıkları, cilt hastalıkları, diyabet, parkinson, alzheimer gibi birçok hastalığı ortaya çıkarmaktadır (Halliwell, 2000; Finkel ve

*Sorumlu Yazar: zehra.murathan@ozal.edu.tr.

Geliş Tarihi: 20 Şubat 2020

Kabul Tarihi: 14 Ekim 2020 
Holbrook, 2000; Mensor ve ark., 2001; Valko ve ark., 2007). Dünya sağlık örgütü (WHO), oksidatif stresin neden olduğu zararlı etkileri ortadan kaldırmak amacıyla doğal ürünlerin tüketimini önermektedir (Murthy ve ark., 2004). Doğal ürünlerin başında organik olarak üretilmiş bitkisel ve hayvansal ürünler, özellikle meyveler gelmektedir. Bitkiler serbest radikallere karşı etkili olan ve biyoaktif bileşenler olarak adlandirılan fenolikler, flavanoidler gibi antioksidan özellikteki bileşenlere sahiptirler. Bu bileşenler serbest radikallerin zararlı etkisini azaltmakta ve radikal kaynakı birçok hastalığın oluşumunu engellemektedir (Cai ve ark., 2003; Yanai ve ark., 2008; Jin ve ark., 2010).

Terminalia, Combretaceae familyasına ait, herdem yeşil ve içerisinde yaklaşık olarak 250 tür barındıran bir genustur (Pfundstein ve ark., 2010). Bu genusa ait olan T.chebula ve T.citrina türleri dünya genelinde çok farklı isimler almaktadır. Myrobalan, haritaki, harad, harada, karkchettu, kadukkaya, king of medicine, halile, harde, harar, sa mao tchet bunlardan bazılarıdır (Aneja and Joshi, 2009; Sharma ve ark., 2011). Bitki daha çok Hindistan, Himalayalar, Bangladeş, Tayvan ve Tibet'te yetişmektedir (Muhammad ve ark., 2012).

T.chebula bitkisi elipsoid, drupa tipinde, sarıdan kahverengiye kadar değişen renklerde, sert kabuklu meyvelere sahiptir, T.citrina ise dünya genelinde sarı myrobalan olarak bilinmektedir. Bitki Kuzey Doğu Hindistan ve Car Nicobar adalarına endemiktir (Chattopadhyay ve Bhattacharyya, 2007; Hajra ve ark., 1999). Meyvelerin organik asitler, flavanoid maddeler, askorbik asit, protein, aminoasitler ve minerallerce zengin olduğu bildirilmiştir (Kim ve ark., 2006; Mahesh ve ark., 2007). Özellikle Uzak Doğuda meyvelerin ayurvedik olarak kullanıldığı bilinmektedir.

Bu çalışmada Türkiye'de aktarlarda satılan, halk tarafından özellikle bağırsak hareketlerini düzenlemek amacıyla kullanılan, $T$. chebula ve $T$. citrina bitkilerinin kurutulmuş meyvelerinin bazı biyoaktif bileşenleri, antioksidan, antibakteriyel ve mutajenik özellikleri araştırılmıştır.

\section{MATERYAL VE YÖNTEM}

\section{Bitki Materyali ve Ekstraksiyon}

Çalışmada kullanılan $T$. chebula ve $T$. citrina bitkilerinin kurutulmuş meyveleri istanbul ilindeki aktarlardan temin edilmiştir. Toz haline getirilmiş olan örneklerin her birinden $15 \mathrm{~g}$ tartılmış ve $300 \mathrm{ml}$ metanol ile Soxhlet sistemi aracilı̆ıyla 8 saat ekstrakte edilmiştir. Elde edilen ekstraktlar daha sonra rotary evaporatörde (Scilogex RE100-Pro) konsantre edilmiş ve analizler yapılıncaya kadar $-20^{\circ} \mathrm{C}^{\prime}$ de bekletilmiştir.

\section{Toplam Fenololik Madde İçeriği}

Toplam fenolik madde içeriği Singleton ve ark. (1999)'nın kullandığı folin-ciocalteu yöntemi kullanılarak tespit edilmiştir. 765 nm'de okuma yapılmış ve elde edilen sonuçlar Gallik asit standart grafiğinde yerine konularak $\mathrm{mg} / \mathrm{g}$ GAE (Gallik asit eşdeğeri) cinsinden hesaplanmıştır.

\section{Toplam Flavanoid Madde İçeriği}

Toplam flavanoid madde tayini Quettier ve ark. (2000)'nın geliştirmiş oldukları yönteme göre belirlenmiş̧ir. $415 \mathrm{~nm}$ dalga boyunda spektrofotometre ile okunmuştur. Quersetin ile hazırlanmış olan kalibrasyon eğrisinden yararlanılarak $\mathrm{mg} / \mathrm{g}$ QE (Quersetin eşdeğeri) cinsinden hesaplanmıştır.

\section{Toplam Antioksidan İçeriği}

Serbest radikallerin indirgenme kapasitesi ABTS (2,2'-azinobis(3-ethylbenzothiazoline-6-sulfonic acid) ve DPPH (1,1diphenyl-2-picrylhydrazyl) metotları ile belirlenmiştir. DPPH metodunda örneklerin absorbansı $515 \mathrm{~nm}$ dalga boyunda spektrofotometrede okunmuştur. Antioksidan kapasite \%DPPH=(Akontrol-Aörnek)/Akontrol $x$ 100)) formülüyle hesaplanmıştır (Bakhshi ve Arakawa, 2006). ABTS yöntemi Re ve ark. (1999)'a göre yapılmıştır. Örneklerin absorbansı 734 nm'de ölçülmüştür. Antioksidan kapasite \%ABTS=(Akontrol-Aörnek)/Akontrol $x$ 100)) formülüyle hesaplanmıştır. FRAP (Demir iyonu indirgeyici antioksidan güç) yöntemi Benzie ve Strain (1996)'e göre yapılmıştır. Absorbans 593 nm'de ölçülmüştür. Standart eğri $\mathrm{FeSO}_{4}$ solüsyonu kullanılarak hazırlanmıştır (100-1000 $\mu \mathrm{l})$. Sonuçlar $\mu \mathrm{mol} \mathrm{Fe}$ (II)/g cinsinden hesaplanmıştır.

\section{Antibakteriyel Aktivite Analizleri}

$T$. chebula ve $T$. citrina örneklerinden elde edilen metanol ekstraktlarının antibakteriyel aktivitesi agar kuyu difüzyon metoduna göre test edilmiştir (Rauha ve ark., 2000). Test bakterisi olarak Bacillus subtilis subsp. spizizenii ATCC 6633, Bacillus licheniformis ATCC 14580, Enterobacter aerogenes ATCC 13048, Pseudomonas aeruginosa ATCC 9027 ve Klebsiella pneumoniae ATCC 33495; pozitif kontrol olarak ise Gentamisin standart antibiyotik kullanılmıştır. Analizler esnasında test maddesi olarak, her bir metanol ekstraktından $150 \mu \mathrm{l}$ kullanılmışır. Analiz sonucunda petriler $37{ }^{\circ} C^{\prime}$ de 48 saat inkübe edilmiş ve oluşan inhibisyon zonları dijital kumpas yardımıyla $\mathrm{mm}$ olarak ölçülmüştür. Analizler üç tekrarlı yapılmıştır.

\section{Mutajen Aktivite Analizleri}

$T$. chebula ve $T$. citrina bitki örneklerinden elde edilen ekstraktların mutajenik aktivitesinin tespitine yönelik analizler, Maron ve Ames (1983) tarafından geliştirilen plak inkorporasyon yöntemine göre yapılmıştır. Mutajen aktivite analizleri Salmonella typhimurium TA 98 ve Salmonella typhimurium TA 100 suşları üzerinde çalışılmıştır. Plaklar $37^{\circ} \mathrm{C}$ 'de $48-72$ saat inkübe edilmiş, bu 
süre sonunda plaklardaki his+ revertant bakteri kolonileri sayılmıştır.

\section{İstatistiksel Analizler}

Çalışmada her analiz 3 tekrarlı olarak yapılmış ve ortalama değerler alınmıştır. Veri analizlerinde SPSS 20 paket programı kullanmıştır. Gruplar arasındaki farklılıklar t testi ile $p<0.05$ önem düzeyinde belirlenmiştir. Mutajenite testlerinde $T$. chebula ve $T$. citrina meyve örneklerinden elde edilen ekstraktların etkisiyle geri dönen koloni sayıları saptanmıştır. Kontrol plakları ile $T$. chebula ve $T$. citrina bitki örneklerinin farklı konsantrasyonlarının denendiği plaklar arasında istatistiksel ayrım olup olmadığı tek yönlü varyans analizini (OneWay ANOVA) takiben Dunnett test metoduna göre araştırılmıştır.

\section{BULGULAR VE TARTIŞMA}

Sekonder metabolitler olarak da adlandırılan fenolik bileşikler, bitkiler tarafından üretilen en önemli ve fonksiyonel bileşenlerdendir. Bitkilerde renk oluşumu, tat oluşumu, aroma oluşumu, bitki savunma sistemlerinin oluşumu gibi faaliyetlerde görev yapmaktadırlar (Çağlar ve Demirci, 2017). Meyvelerdeki fenolik bileşik içeriği bitki türü, çeşidi, kültürel uygulamalar, iklimsel faktörler, hasat zamanı, depolama koşulları gibi çeşitli faktörlere göre değişiklik göstermektedir (Castrejon ve ark., 2008). Çalışmamızda kullanılan örneklerinin toplam fenolik ve toplam flavanoid madde içerikleri Çizelge 1'de gösterilmiştir ve örnekler arasındaki farklar istatistiksel olarak anlamlı bulunmuştur $(p<0.05)$. Örneklerin toplam fenolik madde içerikleri $T$. citrina'da 108.3, $T$. chebula'da $226.3 \mathrm{mg} \mathrm{GAE} / \mathrm{g}$ değerlerinde, toplam flavanoid madde içerikleri ise $T$. chebula'da 40.7, T. citrina'da $55.9 \mathrm{mg} \mathrm{QE} / \mathrm{g}$ değerlerinde tespit edilmiştir. Saha ve Verma (2016) T. chebula kuru meyve ekstraktlarında toplam fenolik madde içeriğinin $134.5 \mathrm{mg} \mathrm{GAE} / \mathrm{g}$, toplam flavanoid madde içeriğinin ise $7.934 \mathrm{mg} \mathrm{QE} / \mathrm{g}$ olduğunu bildirmişlerdir. Wetwitayaklung ve ark. (2012) ise $T$. chebula kuru meyve ekstraktının toplam fenolik madde içeriğinin $6.96 \mathrm{~g} / 100 \mathrm{~g}$ olduğunu
MURATHAN ZT, ERBiL N, ARSLAN M bildirmişlerdir. Das ve ark. (2016) T. citrina'nın metanolik yaprak ekstraktlarında toplam fenolik ve toplam flavanoid madde içeriklerinin sırasıyla $190.23 \mathrm{mg} \mathrm{GAE} / \mathrm{g}$ ve $99.5 \mathrm{mg}$ $\mathrm{QE} / \mathrm{g}$ olduğunu tespit etmişlerdir. Daha önce yapılan çalışmalarda farklı araştırıcılar $T$. chebula'da gallik asit, ellajik asit, tannik asit, etil gallat, chebulajik asit, chebulinik asit, corilagin, beta sitosterol, kafeik asit, terpinen, terpinenol, mannitol, askorbik asit gibi bileşenlerin bulunduğunu tespit etmişlerdir (Kim et al., 2006; Saleem et al., 2002; Xie et al., 2006). T. citrina meyve ekstraktlarında ise punicalagin, corilagin, 1,3,6-tri-O-galloyl-ß-Dglucopyranose, chebulagic acid, ve 1,2,3,4,6-penta-Ogalloyl-ß-Dglucopyranose olmak üzere 5 farklı tanen bulunduğu bildirilmiştir (Burapadaja ve Bunchoo, 1995).

Örneklerin antioksidan aktivite sonuçları Çizelge 1'de verilmiştir. Çalışmada antioksidan aktiviteler üç farklı metotla (ABTS, FRAP ve DPPH) belirlenmiştir. Antioksidan parametre değerlerinde bitkiler arasında istatistiksel olarak önemli varyasyonlar tespit edilmiştir $(p<0.05)$. Her üç metoda göre de $T$. chebula örneklerinin $T$. citrina örneklerine göre daha yüksek antioksidan aktiviteye sahip olduğu belirlenmiştir. Örneklerin ABTS radikali süpürücü aktivitelerinin T. citrina'da \%40.5, T. chebula'da \%59.7, DPPH radikali süpürücü aktivitelerinin $T$. citrina'da \%55.6, $T$. chebula'da \%67.8, FRAP aktivitesinin ise T. citrina'da 61.7 $\mu \mathrm{mol}$ Fell/g, $T$. chebula'da $107.8 \mu \mathrm{mol}$ Fell/g değerlerinde olduğu tespit edilmiştir. Çalışmada kullanılan meyve ekstraktlarının antiradikal aktiviteye sahip olduğu daha önceki çalışmalarda da bildirilmiştir (Cheng ve ark., 2003; Suchalatha ve ark., 2005; Walia ve ark., 2007; Hazra ve ark., 2010). Srivastava ve ark. (2012) T. chebula meyvelerinin DPPH radikali süpürücü aktivitesinin çalışmamızdakine benzer şekilde \%55 olduğunu bildirmişlerdir.

$T$. citrina ve $T$. chebula'dan elde edilen metanol ekstraktlarının ve pozitif kontrol olarak kullanılan gentamisin antibiyotiğinin antibakteriyel aktivitesi Çizelge 2'de sunulmuş olup, elde edilen sonuçlar neticesinde

Çizelge 1. Örneklerin bazı biyoaktif bileşen içerikleri ve antioksidan kapasite analizleri

\begin{tabular}{llllll} 
& $\begin{array}{l}\text { Toplam fenolik } \\
\text { madde miktarı } \\
\text { (mg/g) }\end{array}$ & $\begin{array}{l}\text { Toplam flavanoid } \\
\text { madde } \\
\text { miktarı }\end{array}$ & ABTS (\%) & DPPH (\%) & $\begin{array}{l}\text { FRAP } \\
\text { ( } \boldsymbol{\mu m o l ~ F e ~ I I / g ) ~}\end{array}$ \\
\hline T. chebula & $226.3 \pm 10.5 \mathrm{a}$ & $40.7 \pm 1.6 \mathrm{~b}$ & $59.7 \pm 3.1 \mathrm{a}$ & $67.8 \pm 5.6 \mathrm{a}$ & $107.8 \pm 12.6 \mathrm{a}$ \\
T. citrina & $108.3 \pm 9.6 \mathrm{~b}$ & $55.9 \pm 1.2 \mathrm{a}$ & $40.5 \pm 2.7 \mathrm{~b}$ & $55.6 \pm 0.4 \mathrm{~b}$ & $61.7 \pm 5.1 \mathrm{~b}$ \\
\hline
\end{tabular}

Aynı sütunda gösterilen farklı harfler (a-b) t testine göre istatistiksel olarak farklılıkları göstermektedir $(p<0.05)$.

Çizelge 2. Örneklerin antibakteriyel aktivite sonuçları

\begin{tabular}{llll}
\hline Bakteri & Gentamisin (mm) & T. citrina (mm) & T. chebula(mm) \\
\hline Bacillus subtilis subsp. spizizenii ATCC 6633 & $31.94 \pm 2.62$ & $36.41 \pm 0.48$ & $36.37 \pm 0.38$ \\
Bacillus licheniformis ATCC 14580 & $24.57 \pm 0.70$ & $32.65 \pm 1.95$ & $34.60 \pm 2.56$ \\
Enterobacter aerogenes ATCC 13048 & $19.02 \pm 1.85$ & $22.52 \pm 2.33$ & $23.27 \pm 0.50$ \\
Pseudomonas aeruginosa ATCC 9027 & $27.53 \pm 0.77$ & $34.33 \pm 3.13$ & $30.41 \pm 0.32$ \\
Klebsiella pneumoniae ATCC 33495 & $17.87 \pm 0.24$ & $24.35 \pm 1.72$ & $27.00 \pm 2.93$ \\
\hline
\end{tabular}


T.citrina ve T.chebula'nın metanol ekstraklarının test bakterilerine karşı oldukça iyi seviyede antibakteriyel etki gösterdiği görülmektedir. Her iki ekstrakta karşı en duyarlı bakterinin Bacillus subtilis subsp. spizizenii ATCC 6633 olduğu; oluşan inhibisyon zonu çapının T. citrina için 36.41 $\mathrm{mm}, T$. chebula için ise $36.37 \mathrm{~mm}$ olduğu belirlenmiştir. Daha önce yapılan çalışmalarda T.chebula meyvelerinin Salmonella typhi, Staphylococcus epidermidis, Staphylococcus aureus, Bacillus subtilis and Pseudomonas aeruginosa gibi gram pozitif ve gram negatif bakterilere karşı antimikrobiyal aktiviteye sahip olduğu bildirilmiştir (Malekzadeh ve ark., 2001; Khan and Jain, 2009; Khan, 2009; Khan ve ark., 2009; Manoj kumar ve ark., 2009). Shaider Raza Naqvi ve ark. (2010) Terminalia meyve ekstraktlarının gram pozitif bakterilerde gram negatiflere oranla daha yüksek antimikrobiyal aktivite gösterdiğini tespit etmişlerdir. Yine Malekzadeh ve ark. (2001) bitkinin ekstraktlarının ülser ve gastrit gibi hastalıklara neden olan Helicobacter pylori'ye karşı, Kim ve ark. (2006) Clostridium perfingens ve Escherichia coli'ye karşı etkili olduğunu bildirmiştir. Bitki ekstraktlarının Candida albicans, Epidermophyton, Floccosum, Microsporum gypseum ve Trichophyton rubrum'a karşı antifungal aktivite gösterdiği bilinmektedir (Barazani ve ark., 2003; Vonshak ve ark., 2003). Kumar ve ark. (2009) T. chebula meyve ekstraktının Bacillus subtilis, Staphylococcus aureus, Staphylococcus epidermis, Escherichia coli, Staphylococcus flexineria ve Pseudomonas aeruginosa bakterilerine karşı antimikrobiyal aktivite gösterdiğini belirlemişlerdir. Yine Aneja ve Joshi (2009) bu meyve ekstraktının dental bakterilere karşı oldukça iyi bir antibakteriyel olduğunu tespit etmişlerdir.

Çoğu bitkinin çeşitli bileşenleri yoğun olarak kullanıldığında toksik ve genotoksik etki göstermekte, hatta mutajeniteye sebep olabilmektedirler (Wan-Ibrahim ve ark., 2010). Kimyasal bileşiklerin mutajenik aktivitelerinin araştırılmasına yönelik en yaygın kullanılan testlerden bir tanesi Ames testidir. Bu testte histidin operonunun değişik bölgelerinde çeşitli mutasyonlar içeren Salmonella typhimurium'un mutant suşları kullanılmaktadır (Choy, 2001). Çalışmamızda kullanılan örneklerin mutajenite denemeleri S. typhimurium TA 98 ve TA 100 suşları üzerinde araştırılmıştır (Çizelge 3, 4). Yapılan mutajenite deneylerinde kuru meyve ekstraktlarının farklı dört dozu kullanılmıştır (12.5, 25, 50 ve $100 \mu \mathrm{l} /$ plak). TA 98 ve TA 100 suşları üzerine denenen her iki örnek ekstraktının en yüksek dozları $100 \mu \mathrm{l} /$ plak ile TA 100 suşu üzerinde denenen $T$. citrina ekstraktının $50 \mu \mathrm{l} /$ plak dozları sitotoksik olarak tespit edilmiştir. Bir dozun sitotoksik olduğunun anlaşılması LD50 dozunun altında olmasıyla anlaşılmaktadır. Deneme plaklarındaki koloni sayısının, kontrol plağındaki koloni sayısının yarısının altında olması durumunda doz sitotoksik olarak kabul edilmektedir.

Çizelge 3. Örneklerin Salmonella typhimurium TA 98 suşuna karşı mutajenite sonuçları

\begin{tabular}{|c|c|c|}
\hline & Konsantrasyon & $\begin{array}{l}\text { Revertant koloniler } \\
\text { Ort } \pm S d^{* *}\end{array}$ \\
\hline \multirow[t]{7}{*}{ T. chebula } & Kontrol & $24.00 \pm 2.52$ \\
\hline & $\begin{array}{l}\text { Pozitif Kontrol } \\
(4-N P D)^{*}\end{array}$ & $1375 \pm 162$ \\
\hline & ***ÇK (Metanol) & $16.33 \pm 1.86$ \\
\hline & $12.5 \mu \mathrm{l} /$ plak & $17.00 \pm 3.46$ \\
\hline & $25 \mu \mathrm{l} /$ plak & $17.67 \pm 5.17$ \\
\hline & $50 \mu \mathrm{l} /$ plak & $183.0 \pm 68.7 \mathrm{~b}$ \\
\hline & $100 \mu \mathrm{l} /$ plak & Toksik \\
\hline \multirow[t]{7}{*}{ T. citrina } & Kontrol & $24.00 \pm 2.52$ \\
\hline & $\begin{array}{l}\text { Pozitif Kontrol } \\
(4-N P D)^{*}\end{array}$ & $1375 \pm 162$ \\
\hline & ÇK (Metanol) & $16.33 \pm 1.86$ \\
\hline & $12.5 \mu \mathrm{l} / \mathrm{plak}$ & $16.67 \pm 1.45$ \\
\hline & $25 \mu \mathrm{l} /$ plak & $21.67 \pm 3.84$ \\
\hline & $50 \mu \mathrm{l} /$ plak & $80.7 \pm 11.8 b$ \\
\hline & $100 \mu \mathrm{l} /$ plak & Toksik \\
\hline \multirow{2}{*}{\multicolumn{3}{|c|}{$\begin{array}{l}\text { 4-NPD: 4-nitro-o-phenylened } \\
\text { ***ÇK:Çözücü kontrol } \\
\text { a: Kontrolle örnek arasında öner } \\
\text { b: Çözücü ile örnek arasında öne } \\
\text { Çizelge 4. Örneklerin Salmonella } \\
\text { mutajenite sonuçları }\end{array}$}} \\
\hline & & \\
\hline & Konsantrasyon & Revertant koloniler \\
\hline & & Ort $\pm S d * *$ \\
\hline \multirow[t]{7}{*}{ T. chebula } & Kontrol & $124.00 \pm 9.29$ \\
\hline & $\begin{array}{l}\text { Pozitif Kontrol } \\
(\mathrm{SA})^{*}\end{array}$ & $5226 \pm 520$ \\
\hline & ***ÇK (Metanol) & $107.3 \pm 20.7$ \\
\hline & $12.5 \mu \mathrm{l} /$ plak & $105.0 \pm 19.7$ \\
\hline & $25 \mu \mathrm{l} /$ plak & $69.67 \pm 5.93$ \\
\hline & $50 \mu \mathrm{l} /$ plak & $63.67 \pm 8.82$ \\
\hline & $100 \mu \mathrm{l} /$ plak & Toksik \\
\hline \multirow[t]{7}{*}{ T. citrina } & Kontrol & $124.00 \pm 9.29$ \\
\hline & $\begin{array}{l}\text { Pozitif Kontrol } \\
(\mathrm{SA})^{*}\end{array}$ & $5226 \pm 520$ \\
\hline & ÇK (Metanol) & $107.3 \pm 20.7$ \\
\hline & $12.5 \mu \mathrm{l} /$ plak & $102.3 \pm 10.7$ \\
\hline & $25 \mu \mathrm{l} /$ plak & $88.33 \pm 9.94$ \\
\hline & $50 \mu \mathrm{l} /$ plak & Toksik \\
\hline & $100 \mu \mathrm{l} /$ plak & Toksik \\
\hline
\end{tabular}

"SA:Sodyum azide; ${ }^{* *}$ Sd: Standart hata, ***ÇK:Çözücü kontrol

$T$. chebula ve $T$. citrina ekstraktlarının Salmonella typhimurium TA 98 suşu üzerine etkisi üzerine yapılan çalışmalarda her iki örneğin $50 \mu \mathrm{l} /$ plak dozları çözücü 
kontrole göre istatistiksel olarak önemli bulunmuş ve revertant koloni sayısı her iki ekstraktta da doz artışına bağlı olarak artmıştır (Çizelge 3 ). $T$. chebula ve $T$. citrina ekstraktlarının TA 98 suşu üzerinde denenen diğer dozlarında (12.5 $\mathrm{\mu l} /$ plak, $25 \mu \mathrm{l} /$ plak) ve Salmonella typhimurium TA 100 suşu üzerinde yapılan çalışmaların denenen tüm dozlarında kontrol ve çözücü kontrole göre istatistiksel olarak önem tespit edilememiştir. $T$. chebula ve T. citrina meyve ekstraktlarının mutajenik aktivitesi ile ilgili sınırlı sayıda çalışma mevcuttur. Akhtar ve ark. (2016) T. citrina ekstraktlarının önemli mutajenite gösterdiğini belirtmişlerdir. Etanolik ekstrakt, TA 100 suşu üzerinde daha yüksek mutajenite gösterirken, $T$. citrina'nın sulu ekstraktı, TA 102 suşu üzerine TA 100'den daha yüksek mutajenite göstermiştir. Her iki $T$. citrina özütü doza bağlı mutajenite göstermiştir. Bu çalışmada, T. citrina'nın etanolik ve sulu meyve özütlerinin, mutajenik ve sitotoksik kimyasalları nedeniyle güvenli olamayacağı sonucuna varılmıştır. Bizim yaptığımız çalışmada her iki örneğin yüksek dozları toksik olarak tespit edilirken, TA98 suşu üzerinde her iki örneğin $50 \mu \mathrm{l} /$ plak dozları çözücü kontrole göre istatistiksel olarak önemli bulunmuştur. Ayrıca TA98 suşu üzerinde revertant koloni sayısı her iki ekstraktta da doz artışına bağlı olarak artmıştır. Görüldüğü gibi bizim çalışmamızla Akhtar ve ark. (2016) yaptığı çalışma arasında benzer sonuçlar mevcuttur.

\section{SONUÇ}

Sonuç olarak $T$. chebula ve $T$. citrina meyveleri iyi birer biyoaktif bileşen ve dolaylı olarak da antioksidan kaynağıdırlar. Aynı zamanda kullanılan test mikroorganizmalarına karşı oldukça iyi düzeyde antimikrobiyal aktiviteye de sahiptirler. Bitkiler antioksidan ve antimikrobiyal ajan olarak kullanılabilirler. Bununla birlikte bu bitkiler yüksek dozda alındıklarında toksik etki göstermektedirler. Bu nedenle tıbbi amaçlı kullanımlarının kontrollü şekilde yapılması önem arz etmektedir.

\section{KAYNAKLAR}

Aneja KR, Joshi R (2009) Evaluation of antimicrobial properties of fruit extracts of Terminalia chebula against dental caries pathogens. Jundishapur Journal of Microbiology 2(3): 105-111.

Bakhshi D, Arakawa O (2006) Effects of UV-b irradiation on phenolic compound accumulation and antioxidant activity in 'Jonathan' apple influenced by bagging, temperature and maturation. Journal of Food, Agriculture \& Environment 4 (1): 75-79.

Barazani VO, Sathiyomoorthy P, Shalev R, Vardy D, Golan GA (2003) Screening of South-Indian medicinal plants for anti-fungal activity. Phytotheraphy Research 17(9): 1123-1125.

Benzie IFF, Strain JJ (1996) The ferric reducing Ability of plasma (FRAB) as a measure of "Antioxidant power": The FRAB assay. Analytical Biochemistry 239: 70-76.

Burapadaja S, Bunchoo A (1995) Antimicrobial activity of tannins from Terminalia citrina. Planta Medica 61(4): 365-366.
MURATHAN ZT, ERBiL N, ARSLAN M

Cai YZ, Sun M, Corke H (2003) Antioxidant activity of betalains from plants of the Amaranthaceae. Journal of Agricultural and Food Chemistry 51: 2288-2294.

Castrejón ADR, Eichholz I, Rohn S, Kroh LW, Huyskens-Keil S (2008) Phenolic profile and antioxidant activity of highbush blueberry (Vaccinium corymbosum L.) during fruit maturation and ripening. Food Chemistry 109: 564-572.

Chattopadhyay RR, Bhattacharyya SK (2007) Plant Review Terminalia

chebula. Pharmacognosy Review 23: 145-150.

Cheng HW, Lin TC, Yu KH, Yang CM, Lin CC (2003) Antioxidant and free radical Scavenging activities of Terminalia chebula. Biological and Pharmaceutical Bulletin 26(9): 1331-1335.

Choy WN 2001) Genetic toxicology and cancer risk assessment. Marcel Dekker, New York, 29-187.

Çağlar MY, Demirci M (2017) Üzümsü Meyvelerde Bulunan Fenolik Bileşikler ve Beslenmedeki Önemi. Avrupa Bilim ve Teknoloji Dergisi 7(11): 18-26.

Das N, Goshwami D, Hasan MS, Al Mahmud Z, Raihan SZ (2016) Evaluation of antioxidant, antimicrobial and cytotoxic activities of Terminalia citrina Leaves. Journal of Pharmaceutical Research 10: 8-15.

Duncan DB (1955) Multiplerange and multiple $F$ Tests. Biometrics 11: 1-14.

Finkel T, Holbrook NJ (2000) Oxidants, Oxidative stress and biology of ageing. Nature 239-247.

Hajra PK, Rao PSN, Mudgal V (1999) Flora of AndamanNicobar Islands, Vol-I, Ranunculaceae to Combretaceae, Botanical Survey of India, 480.

Halliwell B (2000) A super way to kill cancer cells? Nature Medicine 6(10): 1105-1106.

Tachakittirungrod S, Okonogi S, Chowwanapoonpohn S (2007)

Study on antioxidant activity of certain plants in Thailand: Mechanism of antioxidant action of guava leaf extract. Food Chemistry 103(2): 381-388.

Hazra B, Sarkar R, Biswas S, Mandal N (2010) Comparative study of the antioxidant and reactive oxygen species scavenging properties in the extracts of the fruits of Terminalia chebula, Terminalia belerica and Emblica officinalis. BMC Complementary and Alternative Medicine 10: 20.

Jin $Y$, Cui $X$, Singh UP, Chumanevich AA, Harmon B, Cavicchia $P$, Hofseth AB, Kotakadi V, Stroud B, Volate SR, Hurley TG, Hebert JR, Hofseth LJ (2010) Systemic inflammatory load in human sissuppressed by consumption of two formulations of dried, encapsulated juice concentrate. Molecular Nutrition \& Food Research 54(10): 1506-1514.

Khan KH, Jain SK (2009) Regular intake of Terminalia chebula can reduce the risk of getting typhoid fever. Advanced Biotech 8(9): 10-15.

Khan KH (2009) The effect of regular intake of Terminalia chebula on oxidative stress in mice originated from Salmonella typhimurium. EurAsia Journal of BioScience 3: 113-121. 
Kim HG, Cho HG, Jeong EY, Lim JH, Lee SH, Lee HS (2006) Growth inhibiting activity of active component isolated from Terminalia chebula fruits against intestinal bacteria. Journal of Food Protection 69(9): 2205-2209.

Mahesh R, Ramesh T, Nagulendran KR, Velavan S, Hazeena BV (2007) Effect of Terminalia chebula on Monoamine Oxidase and Antioxidant enzyme activities in aged rat brain. Pharmacognosy Magazine 3: 12-16.

Malekzadeh F, Ehsanifar $H$, Shahamat M, Levin M, Colwell RR (2001) Antibacterial activity of black myrobalan (Terminalia chebula Retz) against Helicobacter pylori. Journal of Antimicrobial Agents 18: 85-88.

Kumar M, Agarwal RC, Dey S, Rai VK, Johnson B (2009) Antimicrobial Activity of Aqueous Extract Of Terminalia Chebula Retz. on Gram positive and Gram negative Microorganisms. International Journal of Current Pharmaceutical Research 1(1): 56-60.

Maron DM, Ames BN (1983) Revised methods for the Salmonella mutagenicity test. Mutation Research 113: 173-215.

Mensor LL, Menezes FS, Leitao GG (2001) Screening of Brazilian plant extracts for antioxidant activity by the use of DPPH free radical method. Phytotheraphy Research 15: 127-130.

Murthy KB, Nammi S, Kota MK, Krishna Rao RV, Koteswara Rao N, Annapurna A (2004) Evaluation of hypoglycemic and antihyperglycemic effects of Datura metel (Linn.) seeds in normal and alloxaninduced diabetic rats. Journal of Ethnopharmacology 9(1): 95-98.

Muhammad S, Khan BA, Akhtar N, Mahmood T, Rasul A, Hussain I, Khan H, Badshah A (2012) The morphology, extractions, chemical constituents and uses of Terminalia chebula: A review. Journal of Medicinal Plants Research 6(33): 4772-4775.

Pfundstein B, El Desouky SK, Hull WE, Haubner R, Erben G, Owen RW (2010) Polyphenolic compounds in the fruits of Egyptian medicinal plants (Terminalia bellerica, Terminalia chebula and Terminalia horrida): characterization, quantitation and determination of antioxidant capacities. Phytochemistry 71: 11321148.

Quettier-Deleu C, Gressier B, Vasseur J, Dine T, Brunet J, Luyck M, Cazin M, Cazin JC, Bailleul F, Trotin F (2000) Phenolic compounds and antioxidant activities of buckwheat (Fagopyrum esculentum Moench) hulls and flour. Journal of Ethnopharmacology 72: 35-40.

Rauha JP, Remes S, Heinonen M, Hopia A, Kahkonen M, Kujala T, Pihlaja K, Vuorela P (2000) Antimicrobial Effects of Finnish Plant Extracts Containing Flavonoids and Other Phenolic Compounds. International Journal of Food Microbiology 56: 3-12.

Re R, Pellegrini N, Proteggente A, Pannala A, Yang M, RiceEvans C (1999) Antioxidant activity applying an improved ABTS radical cation decolorization assay.
Free Radical Biology and Medicine 26(9/10): 12311237.

Saha S, Verma RJ (2016) Antioxidant activity of polyphenolic extract of Terminalia chebula Retzius fruits. Journal of Taibah University for Science 10(6): 805-812.

Saleem A, Husheem M, Harkonen P, Pihlaja K (2002) Inhibition of cancer cell growth by crude extract and the phenolics of Terminalia chebula retz fruit. Journal of Ethnopharmacology 81(3): 327-336.

Naqvi HR, Asif M, Rehman AB, Ahmad M (2010) Evaluation of antimicrobial properties of Terminalia chebula Retz. Pakistan journal of Pharmacology 27(1): 29-35.

Sharma K, Thakur S, Sharma S, Sharma SD (2012) A New Record on Flowering in Harar (Terminalia chebula Retz.) Seedling. American Journal of Plant Sciences 3: 693-695.

Singleton VL, Orthofer R, Lamuela-Raventós RM (1999) Analysis of total phenols and other oxidation substrates and antioxidants by means of folinCiocalteu reagent. Methods in Enzymology 299: 152178.

Srivastava P, Raut HN, Wagh RS, Puntambekar HM, Kulkarni MJ (2012) Purification and characterization of an antioxidant protein ( $16 \mathrm{kDa})$ from Terminalia chebula fruit. Food Chemistry 131(1): 141-148.

Suchalatha S, Srinivasalu C, Devi S (2005) Antioxidant activity of ethanolic extracts of Terminalia chebula fruit against isoproterenol-induced oxidative stress in rats. Indian Journal of Biochemistry and Biophysics 42: 246- 49.

Valko M, Leibfritz D, Moncol J, Cronin MTD, Mazur M, Telser J (2007) Free radicals and antioxidants in normal physiological functions and human disease. International Journal of Biochemistry and Cell Biology 39: 44-84.

Vonshak O, Barazani P, Sathiyomoorthy R, Shalev D, Vardy D, Golan GA (2003) Screening of South-Indian medicinal plants for antifungal activity. Phytotherapy Research 17(9): 1123-1125.

Walia H, Kumar S, Arora S (2007) Analysis of antioxidant activity of methanol extract / fraction of $T$. chebula Ritz. Journal of Chinese Clinical Medicine 7(2): 1-12.

Wan-Ibrahim WI, Sidik K, Kuppusamy UR (2010) A high antioxidant level in edible plants is associated with genotoxic properties. Food Chemistry 122(4): 11391144.

Wetwitayaklung P, Charoenteeraboon J, Limmatvapirat C, Phaechamud T (2012) Antioxidant activities of some Thai and exotic fruits cultivated in Thailand. Research Journal of Pharmaceutical, Biological and Chemical Sciences 3(1): 12-21.

Xie P, Chen S, Liang Y, Wang X, Tian R, Upton R (2006) Chromatographic fingerprinting analysis-a rational approach for quality assessment of traditional Chinese herbal medicine. Journal of Chromatography A 1112(1-2): 171-180. 
Yanai N, Shiotani S, Hagiwara S, Nabetani H, Nakajima M (2008) Antioxidant combination inhibits reactive
MURATHAN ZT, ERBIL N, ARSLAN M oxygen species mediated damage. Bioscience, Biotechnology, and Biochemistry 72(12): 3100-3106. 
